region-binding site of miR-19a. In the control group, we identified polymorphism rs3093665 in only 1 control. We observed an association between polymorphism rs3093665 and organic brain syndrome $(\mathrm{p}=0.001)$, an association between polymorphism rs3093666 and thrombocytopenia $(\mathrm{p}=0.02)$ and an association between polymorphism rs3093667 and hematuria $(p=0.024)$.

Conclusions To our knowledge, this is the first study to evaluate polymorphisms in miRNA regions of TNFA gene in SLE. We identified polymorphism rs3093665 and rs 3093667, both into miRNA region-binding sites. Alterations contribute to the development of pathological conditions and clinical disorders in SLE.

Funding Source(s): CAPES

$\mathrm{CNPq}$

FAPESP

\section{ASSOCIATIONS BETWEEN PATIENT ACCEPTABLE SYMPTOM STATEAND THREE DOMAINS OF THE DISEASE IN SLE: A CROSS-SECTIONAL STUDY OF 1,364 PATIENTS FROM THE SPANISH SOCIETY OF RHEUMATOLOGY LUPUS REGISTRY} ${ }^{4}$ Javier Narváez-García, ${ }^{5}$ Francisco Javier López-Longo, ${ }^{6}$ Maria Galindo Izquierdo, ${ }^{7}$ Jaime Calvo Alen, ${ }^{8}$ Antonio Fernandez Nebro, ${ }^{5}$ Juan Ovalles-Bonilla, ${ }^{9}$ Paula Rubio Muñoz, ${ }^{10}$ Eva Tomero Muriel, ${ }^{3}$ Coral Mouriño Rodriguez, ${ }^{11}$ Esther Uriarte Isacelaya, ${ }^{12}$ Angela Pecondón Español, ${ }^{13}$ Mercedes Freire González, ${ }^{14}$ Ricardo Blanco Alonso, ${ }^{15}$ Marian Gantes Mora, ${ }^{16}$ Monica Ibañez Barcelo, ${ }^{17}$ Carlos Montilla Morales, ${ }^{3}$ Jose Maria Pego Reigosa. 'Hospital Universitario Lucus Augusti; ${ }^{2}$ Hospital de Gran Canaria DR. Negrín; ${ }^{3}$ Complexo hospitalario Universitario Vigo; ${ }^{4}$ Hospital de Bellvitge; ${ }^{5}$ Hospital General Universitario Gregorio Marañón; ${ }^{6}$ Hospital Universitario 12 de Octubre; ${ }^{7}$ Hospital Universitario Araba; ${ }^{8}$ UGC de Reumatología, Instituto de Investigación Biomédica de Málaga (IBIMA) Hospital Regional Universitario de Málaga, Spain; ${ }^{9}$ Hospital Germans Trias I Pujol; ${ }^{10} \mathrm{Hospital}$ de la Princesa; ${ }^{11} \mathrm{Hospital}$ de Donostia; ${ }^{12} \mathrm{Hospital}$ Miguel Servet; ${ }^{13} \mathrm{Hospital}$ Juan Canalejo A Coruña (CHUAC); ${ }^{14}$ Hospital Marques de Valdecilla; ${ }^{15}$ Hospital Universitario de Canarias; ${ }^{16}$ Hospital Son Llàtzer de Palma de Mallorca; ${ }^{17}$ Hospital Clinico Universitario Salamanca

10.1136/lupus-2019-Ism.245
Background In a large cohort of systemic lupus erythematosus (SLE) patients, to evaluate the association between a Patient Acceptable Symptom State (PASS) and three different domains of the disease: activity, damage and impact of SLE on patients lives.

Methods Cross-sectional study of 1,364 SLE (ACR 97 Criteria) patients from the Spanish Society of Rheumatology Lupus Registry (RELESSER). Patients were clinically assessed by the physicians, who collected data about demographics, clinical manifestations, laboratory features and therapies. SLE activity was assessed by using the SLEDAI (SLE Disease Activity Index). The Systemic Lupus International Collaborating Clinics/American College of Rheumatology Damage Index (SLICC/ACR DI) was used to measure damage accrual. The impact of SLE on patients lives was evaluated by using the Lupus Impact Tracker (LIT). Finally, the PASS question 'Considering all the different ways your disease is affecting you, if you would stay in this state for the next months, do you consider that your current state is satisfactory? was answered in a dichotomized way: yes/no. Measures of central tendency and spread were used to describe responses and T-test was used to evaluate the independence between PASS and the other questionnaires and indices.

Results Mean age (years) \pm S.D. of the 1364 patients included in the study was $49.9 \pm 13.3 ; 90.3 \%$ were female and $94.9 \%$ were Caucasian. In the total of patients, 979 (71.8\%) were in PASS. Patients in PASS had significantly lower activity (SLEDAI Score) than those not in PASS $(2.4 \pm 3.2$ vs. $3.0 \pm 3.9$, respectively; $\mathrm{p}=0.007)$. The SLICC/ACR DI was significantly lower in the group of patients in PASS compared to those without PASS $(0.64 \pm 1.1$ vs. $0.81 \pm 0.21$, respectively; $\mathrm{p}=0.022$ ). SLE had a significantly lower impact on patients in PASS in comparison to those without PASS (LIT Score: 8.47 \pm 7.5 vs. $19.8 \pm 8.34$, respectively; $\mathrm{p}=0.001$ ). Distribution and statistics for each group are shown in table 1.

Conclusions In the largest observational European Registry of SLE patients, PASS was associated with other domains of the disease: activity, damage and impact on patients life. PASS is a simple and reliable patient-reported outcome that can be a useful tool to evaluate patients well-being.

Funding Source(s): None

\begin{tabular}{|c|c|c|c|c|c|c|}
\hline \multicolumn{7}{|c|}{ Abstract 245 Table 1} \\
\hline & & $\mathrm{n}$ & Mean & $\pm S D$ & $P$ value & Cohen's d size effect \\
\hline \multirow[t]{2}{*}{ SLEDAI } & PASS yes & 969 & 2.40 & 3.27 & \multirow[t]{2}{*}{0.007} & \multirow[t]{2}{*}{$0,18(0,06-0,30)$} \\
\hline & PASS no & 380 & 3.02 & 3.96 & & \\
\hline \multirow[t]{2}{*}{ SLICC ACR } & PASS yes & 969 & 0.64 & 1.10 & \multirow[t]{2}{*}{0.01} & \multirow[t]{2}{*}{$0.15(0.03-0.27)$} \\
\hline & PASS no & 380 & 0.81 & 1.21 & & \\
\hline \multirow[t]{2}{*}{ LIT } & PASS yes & 962 & 8.47 & 7.53 & \multirow[t]{2}{*}{0.001} & \multirow[t]{2}{*}{$1.46(1.33-1.59)$} \\
\hline & PASS no & 375 & 19.81 & 8.34 & & \\
\hline
\end{tabular}

